\section{Toxische Dosis}

C. Vidal ${ }^{1}$ und W.-R. Külpmann ${ }^{2}$

${ }^{1}$ Landeskriminalamt Niedersachsen, Dezernat 53 „Chemie“, Hannover, Deutschland

${ }^{2}$ Hannover, Deutschland

\section{$\operatorname{Synonym(e)} \mathrm{TD}_{50}$}

Englischer Begriff toxic dose
Definition Dosis, bei der $50 \%$ einer toxischen Wirkung auftreten oder im Kollektiv 50 \% der Individuen eine toxische Wirkung zeigen.

\section{Literatur}

Forth W, Henschler D, Rummel W (1987) Allgemeine und spezielle Pharmakologie und Toxikologie. BI Wissenschaftsverlag, Mannheim 